\title{
DESTINATION ATTRIBUTES AND CHINESE OUTBOUND TOURISM TO
}

\section{EUROPE}

\author{
Rosario Andreu, Enrique Claver and Diego Quer \\ University of Alicante, Spain
}

\begin{abstract}
China is one of the fastest growing outbound tourism markets. Europe is an attractive destination for Chinese tourists. However, Europe still accounts for a small percentage of Chinese outbound tourism. If European countries want to benefit from this market, they should pay attention to Chinese tourists' preferences. This paper contributes to the understanding of Chinese outbound tourism by analyzing those destination attributes that can influence on the number of Chinese tourists received. From a sample of 47 European countries, our findings suggest that a greater cultural distance from China, a large number of World Heritage Sites, a large ethnic Chinese population and a large number of flight connections to China are associated with the amount of Chinese tourists visiting each country.
\end{abstract}

Keywords: China; Europe; destination; cultural distance; heritage wealth; flight connections. 


\section{INTRODUCTION}

Tourism in China has become a rapidly growing industry of great economic importance in the country's globalization process (Ma, Ryan \& Bao, 2009). Tourism plays a strategic role in the development of China towards a market socialist economy (Xiao, 2006). Tourism in China is still considered a young industry (Zhang, Pine \& Zhang, 2000), especially as far as outbound tourism is concerned. There is a consensus that outbound tourism from mainland China started in the early 1980s and has gone through three stages: travel to Hong Kong and Macao, travel to the border regions and intra-Asia countries, and travel to foreign countries beyond Asia (Yun \& Joppe, 2011).

Despite its late start, China has become one of the world's most important tourism powers. According to data provided by the World Tourism Organization (UNWTO, 2011), China climbed up one position in the country ranking in 2010 , both by number of international tourist arrivals and by the income obtained from international tourism. Thus, China ranks third regarding number of arrivals (after France and the United States, ousting Spain and having overtaken both the United Kingdom and Italy during the past few years). China also ranks fourth in terms of income (after France, Spain and the United States, overtaking Italy).

Its high growth rate along with its incredible and unprecedented rise in ranking positions during the last few years make it easy to expect that China will soon become the world's first tourism power, just as the World Tourism Organization had already announced in its forecasts years ago. More precisely, China is expected to attract 210 million foreign tourists and the number of outbound tourists from China would reach 100 million by 2020 (UNWTO, 2004); which will make it become the world's first tourism destination and the fourth largest outbound tourism market.

In the light of these promising data, there are many countries interested in attracting those Chinese tourists who will travel abroad in the coming years because this means 
unquestionable opportunities for economic growth. With Chinese outbound tourism growing rapidly, this topic has increasingly interested observers inside and outside China (Qun \& Jie, 2001). Although there is still little research on the trips abroad of tourists from mainland China (Sparks \& Pan, 2009) and the Chinese outbound tourism market overall remains unknown to most Western marketers (Li, Harrill, Uysal, Burnett \& Zhan., 2010), in the last years there has been an intensification of studies meant to explore the Chinese tourism phenomenon (Andreu, Claver \& Quer., 2010).

Most of the Chinese tourists who travel beyond the borders of their country still have geographically and culturally close Asian countries as their destination. However, in recent years, there is a growing trend toward travel to countries situated at a greater geographical distance; i.e. long-haul destinations, defined as those that require more than six hours of flying time (Lui, Kuo, Fung, Jao \& Hsu., 2011). More specifically, Europe has become the most popular long-haul destination among Chinese tourists in recent years (Xie \& Li, 2009). Furthermore, it is the continent with the highest number of Approved Destination Status countries. This justifies the interest in the study of Chinese tourism across Europe.

However, not all European countries are benefiting to the same extent from the growth of Chinese outbound tourism. The European countries preferred by these tourists include France, which received 567,294 Chinese tourists in 2010; Germany, which received 510,000 or Switzerland, which received 286,420 (China Tourism Academy [CTA], 2011). It is therefore necessary to carry out a study about the possible reasons that justify why these Chinese tourists prefer traveling to some European destinations rather than to others. Moreover, few works have analyzed the positioning of those foreign destinations which Chinese tourists are interested in visiting (Kim, Guo \& Agrusa, 2005).

Among the possible explanations about why Chinese tourists mostly continue to travel to Asian countries, cultural differences are likely to play a role (Li, Lai, Harrill, Kline \& Wang., 
2011; Pacific Asia Travel Association (PATA), 1995). In other words, cultural distance can influence the decision to visit a destination. However, cultural differences have been largely ignored in the study of destination choice by Chinese tourists (Jackson, 2001; Ng, Lee \& Soutar, 2007; Poolprasert, 2009). Most of the research papers that include demand prediction models have been exclusively based on economic variables. Furthermore, they have generally analyzed the perceptions of Chinese citizens about certain destinations in order to check these tourists' intention to visit them. Those perceptions are subjective and very often not too reliable, since the interviewed citizens do not even know the destination under study. On the other hand, there are very few papers analyzing Chinese tourists' attitudes towards multiple or competing tourism destinations (Yun \& Joppe, 2011).

In order to fill this gap, this paper tries to contribute to a better knowledge of Chinese outbound tourism, analyzing which factors can influence the Chinese tourist's decision to visit a specific destination in the European context. More precisely, our aim is to check whether cultural distance and other destination attributes play a relevant role in the decision to visit different countries in the European continent. Unlike most of the previous research, our empirical study is based on objective data, taking as a reference the number of Chinese tourists who have finally decided to visit a country. This paper consequently offers a different point of view, as it analyses the decision to visit a country once that decision has been made. The results obtained may help complement those of previous papers that have examined the decision before being adopted and implemented by the potential tourists.

The findings of this paper will be useful for public administrations and tourism sector entrepreneurs to know the Chinese tourist's profile and to adapt their strategies to this specific type of tourist accordingly. Knowing the factors that may influence the choice of a destination by Chinese tourists will contribute to improve tourism policies and make decisions required to attract a higher number of these tourists. This will facilitate a better 
adaptation of destination promotion and marketing strategies to Chinese citizens. Identifying the destination behavior and attributes most highly valued by Chinese tourists is undoubtedly of great interest for people in charge of tourism matters worldwide, since this will give them the chance to position themselves properly in the fight for this promising market.

\section{CHINESE TOURISM IN EUROPE: DESCRIPTIVE ANALYSIS}

\subsection{Chinese tourist's profile}

Despite the growth of Chinese outbound tourism in recent years, the percentage of Chinese citizens who made long-distance trips in 2010 only reached $1.3 \%$. According to the CTA (2011), long-distance Chinese tourists are people with a high purchasing power and belonging to a middle-high social class. Their age ranges between 25 and 44 years; $52.98 \%$ of them are men and $81 \%$ have completed higher studies. As for their occupation, there are professionals in the educational sector $(11.75 \%)$, manufacturing industry workers $(9.63 \%)$, employees working in sectors such as finance (8.31\%) and new technologies $(7.91 \%)$, students (6.79\%), as well as scientists and researchers $(5.71 \%) .68 .36 \%$ of these tourists traveled abroad for the first time in 2010 , whereas $31.64 \%$ had done it before. They usually travel accompanied by relatives or by their spouse (46.98\%), by friends (23.81\%), and by work or study partners (13.66\%); only $6.95 \%$ of them travel alone. Regarding monthly per capita income, the most numerous Chinese tourists are those earning between 550 and 880 euros $(29.76 \%)$, followed by those whose salary ranges from 330 to 550 euros $(26.25 \%)$ and the ones who earn between 880 and 1,100 euros (17.46\%).

Concerning the dates on which they usually travel, the main holiday periods in China coincide with the Spring Festival or Chinese New Year (between January and February), Labor Day (May $1^{\text {st }}$ ) and the People's Republic of China National Day (October $1^{\text {st }}$ ). Other traditional festivities include the Qingming Festival (equivalent to All Saints' Day, in April), 
the Dragon Boat Festival (celebrated with dragon-shaped boat races, in June) and the MidAutumn Festival (related to the full moon, between September and October). In 1999, the government introduced the three weeks of holidays that were later reduced to two weeks in 2008. The number of statutory holidays also increased from 10 to 11 and several traditional festivities were added (Xie \& Li, 2009). This new holiday policy has contributed to domestic tourism growth.

Most of the Chinese tourists still travel in organized groups due to cultural distance and linguistic barriers, because it is easier to obtain a visa and because that is the option preferred by those who have no previous experience in traveling abroad, especially to remote places such as Europe and Oceania. Nevertheless, individual trips are expected to increase in the next few years, particularly among experienced tourists. This trend has already become visible in trips to Asian destinations and is expected to appear in long-haul destinations. This is because some Chinese tourists not only have greater purchasing power but also better educational level and better knowledge of other languages. ${ }^{1} 40.8 \%$ of them visit between one and two countries in the same trip; $31.6 \%$ visit between five and 11 countries; and $27.6 \%$ visit between three and four countries.

The average length of stay for tourists in Europe amounts to 9.2 days. If each European country is analyzed on an individual basis, the average is lower than that of the continent as a whole: Germany (2.1 days), France (2 days), Italy (1.6 days), etc. The exception is provided by the United Kingdom with 21 days, because this country does not belong to the Schengen area (it is not included in multi-destination tours) and receives a higher number of tourists for reasons related to studies and family gatherings (Tomás, 2011).

\footnotetext{
${ }^{1}$ In the future, it is expected that Chinese tourist will be near the venturer profile proposed by Plog (2001: 1718). The venturers prefer to be on their own on international trips, even when they don't speak the language, rather than be part of a regimented escorted tour. They are active when travelling, they travel more frequently because travel is an important part of exploring the world around them, they spend more each day per capita, they prefer to participate in local customs and habits, they take relatively long trips, etc.
} 


\subsection{Chinese tourists to Europe}

\section{Main European destinations}

Although Chinese tourists visit Western European countries such as Germany, the United Kingdom or France, there has been a growing interest in Northern and Eastern European countries like Poland (Xie \& Li, 2009). Table 1 reports the main European destinations for Chinese outbound tourism in 2010.

Table 1: The 10 main European destinations for Chinese tourism in 2010

\begin{tabular}{cll}
\hline European destination & Number of Chinese tourists \\
\hline 1. & Russia & 710,900 \\
2. & France & 567,294 \\
3. & Germany & 510,611 \\
4. & Switzerland & 286,420 \\
5. & Austria & 182,282 \\
6. & Italy & 148,000 \\
7. & Holland & 126,000 \\
8. & United Kingdom & 108,037 \\
9. & Spain & 102,000 \\
10. & Belgium & 79,908
\end{tabular}

Source: Tomás (2011), based on data from the China Outbound Tourism Research $I n s t i t u t e$ (COTRI)

China became the first Asian country in terms of incoming tourists to Europe in 2010 (ITB, 2011). This continent actually receives $25 \%$ of the total Chinese outbound tourism, as opposed to $17 \%$ of Japanese and Indian outbound tourism. Germany and France will probably continue to be the most attractive European countries for Chinese tourists thanks to the strong commercial relationships and the improved flight connections (Antonioli Corigliano, 2011). 


\section{Travel motives of Chinese tourists to Europe}

The main reasons adduced by Chinese tourists for visiting Europe are the following (Tomás, 2011): beauty and landscape (82\%); historic and cultural wealth (73.6\%); charming cities (43.5\%); exoticism of its culture and folklore (23\%); being a shopping paradise (21.9\%); good tourism facilities (16\%); and the entertainment/leisure supply (6.7\%). On the other hand, among the most influential factors in choice destination by Chinese tourists stand out: places of interest (37.32\%); price (27.45\%); leisure possibilities (11.15\%); transport (11.07\%); accommodation (6.19\%); and food and drink (5.99\%). The choice is also influenced by destination security, hygienic conditions in the area or lesser difficulty in visa formalities.

In short, Chinese tourists above all seek to know new cultures and live new experiences, especially those who travel to distant destinations like Europe, which meets the expectations of Chinese tourists in terms of high-cultural-level attractions (Arlt, 2011a). Related to this, there is a Chinese proverb highlighting the importance of travel for knowledge acquisition, stating that 'one learns more by traveling ten thousand miles than reading ten thousand books' (Tse \& Hobson, 2008). Therefore, these descriptive data suggest that the Chinese tourist who travels to Europe chooses to visit a specific country because of its historic, natural and cultural heritage, additionally taking into account the level of development of tourism infrastructures in that particular country as well as other factors such as destination security. After identifying the Chinese tourist's profile and providing some descriptive data, in the next section we propose several hypotheses regarding the relationship between some factors affecting the decision to visit a European destination and the number of Chinese tourists that it receives. 


\section{THEORETICAL FRAMEWORK AND HYPOTHESES}

\section{Cultural distance}

Chinese culture exerts a strong influence on the behavior of Chinese tourists who travel beyond the borders of their country (Yang, Reeh \& Kreisel, 2011). Therefore, it needs to be considered in the study of Chinese outbound tourism. Analyzing cultural distance between destinations acquires great importance in those cases where tourism between long-haul tourism markets is studied (Antonioli Corigliano, 2011). Despite the relevance of cultural differences when it comes to decide what specific country to visit, few studies have tried to analyze this issue (Ng et al., 2007; Poolprasert, 2009). Culture may have an influence on the motivations to travel, on the image of a destination, on the trip organization, etc. However, most of the studies which have developed demand prediction models have focused on including economic variables, leaving aside a whole set of socio-cultural variables which are also likely to influence the decision to travel to a specific destination.

Four main cultural elements impact on the choice of a tourism destination (Poolprasert, 2009): the tourist's national culture; the extent to which the tourist has internalized culture; the destination's culture (formed by tangible and intangible elements: museums, historic sites, heritage wealth, etc.) and cultural distance. Although some papers suggest that the more similarity between the culture in the country of origin and that in the country of destination, the greater likelihood of visiting that country (Basala \& Klenosky, 2001; Lepp \& Gibson, 2003), there are also studies which suggest the opposite. Taking as a reference the cultural dimensions of Hofstede (1980), Jackson (2001) reports that tourists coming from countries with more individualistic cultures tend to travel to destinations which are culturally more similar; instead, if they are less individualistic (as is the case in China), they usually travel to 
destinations with fewer cultural similarities ${ }^{2}$. China is considered a country with a low degree of individualism, which is why its tourists will most probably feel motivated to visit countries with cultures different from theirs. In fact, as we stated above, Chinese tourists are considered cultural tourists who travel mainly motivated by the desire to know the history and lifestyle of countries which are unknown to them.

Reisinger and Crotts (2010) point out that cultural differences attract tourists to a particular destination, and conclude that the cultural dimensions described by Hofstede (1980) can be useful to analyze tourist trends for different countries. In addition, Du and Dai (2008) found that, in the case of Chinese tourists, the first consideration when it comes to choose a trip abroad is the destination's culture rather than the price. This is a consequence of the growing maturity in the Chinese tourism market. All these ideas lead us to propose our first hypothesis:

Hypothesis 1: The cultural distance between China and the country of destination will positively influence the number of Chinese tourists who visit that country.

\section{Other destination attributes}

The cultural and natural attractions offered by European cities, with their traditions, folklores and landscapes are one of the reasons which lead Chinese tourists to visit Europe. Yun and Joppe (2011) reported that cultural experiences and nature activities were the most important attractions for Chinese tourists in seven long-haul destinations. Among them, European countries were preferred by Chinese tourists to visit historic and cultural attractions.

Along with places of interest, Chinese tourists also appreciate the existence of good tourism infrastructures (hotels, transports, etc.) and security and hygienic conditions at the

\footnotetext{
${ }^{2}$ Although Hofstede's dimensions have not been widely used in tourism research, there are several studies on tourism that have used these dimensions, such as those of Jackson (2001), Ng, Lee and Soutar (2007) and Reisinger and Crotts (2010).
} 
destination. More specifically, Kim et al. (2005) found that the attributes related to destinations which Chinese tourists are most concerned about are destination security, environmental beauty, tourism facilities, differences in culture and historic resources with respect to China, and good climate. Similarly, Sparks and Pan (2009) concluded that infrastructure quality is the second best valued destination attribute among long-distance Chinese tourists after its landscape beauty. Therefore, a positive relationship can be expected between the heritage wealth, the availability of tourism infrastructures and destination security and the number of Chinese tourists who visit each country. Thus, we propose the following hypotheses:

Hypothesis 2: The country of destination's heritage wealth will positively influence the number of Chinese tourists who visit that country.

Hypothesis 3: The country of destination's tourism infrastructure availability level will positively influence the number of Chinese tourists who visit that country.

Hypothesis 4: The country of destination's security level will positively influence the number of Chinese tourists who visit that country.

\section{Number of Chinese inhabitants}

Another factor that can play a relevant role when it comes to visit a destination is the number of Chinese inhabitants residing in the country. The number of residents of Chinese nationality has considerably increased at certain destinations. This increase is likely to cause an intensification of the trips made by Chinese citizens to visit relatives or friends who reside in that country. Along this line of reasoning, Antonioli Corigliano (2011) argues that, since deep-rooted Chinese communities exist in Italy, visiting friends and relatives is most probably the main motivation among the Chinese tourists who travel to this country. 
On the other hand, the existence of those communities has been used in several papers as a measure of cultural distance, insofar as the existence of a large number of inhabitants of Chinese origin in the country of destination will probably facilitate adaptation to local customs (Buckley et al., 2007; Quer, Claver \& Rienda, 2012). Thus, we propose:

Hypothesis 5: The percentage of Chinese immigrant population in the country of destination will positively influence the number of Chinese tourists who visit that country.

\section{DESCRIPTION OF THE EMPIRICAL RESEARCH}

\subsection{Sample and data}

Data were obtained from the European Travel Commission (ETC) (2011), similarly to what had been done by Xie and Li (2009). The report published by this organization lists the European countries that receive a higher number of Chinese tourists, grouping them together in several categories (Table 2).

Table 2: European countries by number of Chinese tourist arrivals (2010)

\begin{tabular}{lc}
\hline Countries & Chinese tourists \\
\hline Russia, France & $500,000-1,000,000$ \\
Germany, Italy & $250,000-500,000$ \\
Austria, Belgium, Holland, Spain, Switzerland, United Kingdom & $100,000-250,000$ \\
Czech Republic, Denmark, Finland, Greece, Sweden, Turkey & $50,000-100,000$ \\
Hungary, Portugal & $25,000-50,000$ \\
Norway, Poland, Romania, Ukraine & $10,000-25,000$ \\
Bulgaria, Croatia, Iceland, Ireland, Latvia, Luxembourg, Slovakia, & $5,000-10,000$ \\
Slovenia & \\
Albania, Armenia, Azerbaijan, Belarus, Bosnia and Herzegovina, & $<5,000$ \\
Estonia, Cyprus, Georgia, Liechtenstein, Lithuania, Macedonia, Malta, & \\
Moldova, Monaco, Montenegro, San Marino, Serbia & \\
\hline
\end{tabular}


Russia and France are the countries that attract more Chinese tourists. Nevertheless, other countries have improved their ability to attract Chinese tourism, such as Germany, Italy, Austria, Switzerland and Turkey. Our sample is made up of the 47 European countries included in Table 2, grouped together according to the number of Chinese tourists that they received in 2010. There are still many countries which do not collect specific data about the number of Chinese tourists received; hence the need to group them by intervals.

\subsection{Measures}

\section{Dependent variable}

The dependent variable in our study is the number of Chinese tourists that each European country receives. This is a categorical variable with eight categories. The intervals collected in Table 2 were taken as a reference. Thus, the countries which have received less than 5,000 Chinese tourists are placed in category one; those which have received between 5,000 and 10,000 Chinese tourist in category two; and so on and so forth up to the countries receiving between 500,000 and 1,000,000 Chinese tourists, which belong to category eight. These data are taken from the European Travel Commission that groups the European countries in these eight categories based on the number of Chinese tourists.

\section{Independent variables}

Kogut and Singh's index (1988) was used to measure cultural distance (Hypothesis 1) $)^{3}$. We calculated the difference between China and each European country for each dimension of the new model developed by Hofstede, Hofstede and Minkov (2010): power distance, individualism, masculinity, uncertainty avoidance, long-term orientation, and indulgence

\footnotetext{
${ }^{3}$ Although Kogut and Singh's index has been subjected to some criticism, Ng, Lee and Soutar (2007) compared five measures of cultural distance between tourism destinations, one of them being that of Kogut and Singh. The five measures were found to be highly correlated with each other.
} 
versus restriction. We used the data of another culturally similar country for those countries not collected in the model (Erramilli, 1991). The Kogut and Singh's Index is the following:

$$
\mathrm{CD}_{\mathrm{j}}=\sum\left\{\left(\mathrm{I}_{\mathrm{ij}}-\mathrm{I}_{\mathrm{iu}}\right)^{2} / \mathrm{V}_{\mathrm{i}}\right\} / 6
$$

Were $I_{i j}$ stands for the index for the $i^{\text {th }}$ cultural dimension and $j^{\text {th }}$ country, $u$ indicates China, $\mathrm{V}_{\mathrm{i}}$ is the variance of the index of the $\mathrm{i}^{\text {th }}$ dimension, and $\mathrm{CD}_{\mathrm{j}}$ is cultural difference of the $\mathrm{j}^{\text {th }}$ country from China.

We measured each country's heritage wealth (Hypothesis 2) using the number of World Heritage Sites (both natural and cultural, and mixed or immaterial) owned by that country, recognized by United Nations Educational Scientific and Cultural Organization (UNESCO) (2012).

The tourism infrastructure availability and destination security levels were proxied using the Travel and Tourism Competitiveness Index (World Economic Forum, 2011), which measures various aspects related to tourism businesses and regulations with the aim of improving countries' competitiveness. This index is developed within the context of 'the World Economic Forum's Industry Partnership Programme for the Aviation, Travel and Tourism Sector' through surveys carried out among important organizations such as the International Air Transport Association, the International Union for Conservation of Nature, the World Tourism Organization and the World Travel and Tourism Council. This index, valued in one-to-seven scale is in turn divided into several sub-indexes valued within the same scale, two of which were used in this paper. One of them was 'TandT business environment and infrastructure', which values aspects associated with transport infrastructures, hotel infrastructures, price level, etc., and served as a measure of the different countries' tourism infrastructure availability levels (Hypothesis 3).

Another of the sub-indexes is 'TandT Regulatory Framework', which includes the assessment of regulations and policies in the country, security at the destination, health and 
hygiene, environmental sustainability measures, etc., and was used to measure the destination security level (Hypothesis 4). Regarding the number of Chinese inhabitants in each country (Hypothesis 5), data obtained from Ohio University (2012) were used to calculate the percentage of Chinese citizens over the total population (Buckley et al., 2007; Quer et al., 2012). The data were complemented using other official statistical sources such as Statistical Office of the European Communities and Organization for Economic Cooperation and Development.

\section{Control variables}

The decision to travel to a particular destination may be influenced by other factors such as geographical distance, visa policy, number of authorized travel agencies, or flight connections. In our case, geographical distance was not taken into account because Europe as a whole is considered a long-haul destination by Chinese citizens and the geographical distance between the different European countries is not so big as to represent a discriminating factor when it comes to make the decision about where to travel.

On the other hand, although visa system is not homogeneous among the 47 European countries, most of them are making great efforts to improve their visa granting policy seeking to attract these Chinese tourists. New consulates have been opened in China during the last few years for speeding up formalities, and the requirements demanded for the granting of a visa are being softened too. Many countries want to benefit from the rise of Chinese outbound tourism and have accordingly simplified their visa granting policy (Xie \& $\mathrm{Li}$, 2009). For example, they have relaxed the restrictions to the number of people traveling in groups, or have permitted to travel freely when, in the past, it was necessary for tourists to travel in a group with a package tour. Therefore, no significant differences in visa granting policy are expected to exist between European countries in general terms. 
Where differences can actually be detected is in the number of travel agencies authorized by the government of each country to receive Chinese tourists who travel in groups. According to data provided by the CTA (2011), these agencies, the number of which has grown in recent years, contribute to maintain tourism quality, help protect the legitimate rights and interests of Chinese citizens and permit to know their satisfaction level. In short, they represent a guarantee and increase destination security for Chinese tourists. That is why we have chosen the number of travel agencies authorized to receive Chinese tourists in each European country as a control variable. This information was drawn from the Annual Report of China Outbound Tourism Development 2011 (CTA, 2011). Differences equally appear regarding the existence of good flight connections between China and the different European countries. For this reason, the number of airports offering direct connections with China from each European country was considered a control variable. This information was obtained from the ETC (2011).

Data for all these variables for the 47 European countries are listed in Appendix 1.

\section{RESULTS AND DISCUSSION}

Because various factors impact on Chinese travelers' choice, multivariate analysis techniques that account for the overall effects of different variables would be appropriate. Since the dependent variable includes more than two ordered categories, we test the hypotheses using an Ordinal Regression model. The link function used to estimate the model was Log-log-negative, the lower categories being the most likely because they accumulated a higher number of observations. In any case, the model results do not vary if any other link function is used. Table 3 shows the correlation matrix, the descriptive statistics, and the multicolinearity analyses. 
Table 3: Statistics, correlations and variance inflation factor (VIF)

\begin{tabular}{|c|c|c|c|c|c|c|c|c|c|}
\hline & Mean & SDD & 1 & 2 & 3 & 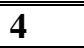 & 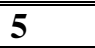 & $\overline{6}$ & VIF \\
\hline 1. Cultural distance & 3.06 & 1.21 & & & & & & & 1.69 \\
\hline 2. Heritage wealth & 0.04 & 1.00 & 0.01 & & & & & & 2.27 \\
\hline 3. Tourism infrastructures & 3.18 & 1.61 & $0.54 * *$ & $0.42 * *$ & & & & & 3.47 \\
\hline 4. Security & 4.73 & 0.89 & $0.59 * *$ & 0.08 & $0.64 * *$ & & & & 2.51 \\
\hline 5. Chinese population & 0.15 & 0.24 & 0.23 & $0.30 *$ & $0.49 * *$ & 0.24 & & & 1.47 \\
\hline 6. Airports with connection & 0.03 & 1.01 & $0.05^{*}$ & $0.64 * *$ & $0.34 *$ & 0.02 & $0.34 *$ & & 1.80 \\
\hline 7. Travel agencies & -0.08 & 0.94 & 0.05 & $0.50 * *$ & 0.25 & 0.06 & 0.04 & $0.35^{*}$ & 1.39 \\
\hline
\end{tabular}

According to Hair, Anderson, Tatham and Black (2005), the existence of a high correlation (generally values of at least 0.90 ) may be a sign of colinearity problems. One of the most common measures used to check this is the Variance Inflation Factor (VIF), which indicates the degree to which each independent variable is explained by other independent variables. Neter, Wasserman and Kutner (1996) established that a Variance Inflation Factor above 10 means that colinearity could be excessive, to such an extent that it might have an influence on the correct model estimate. Table 3 reports that Variance Inflation Factor level is low for all variables, the highest value being 3.47. Thus, colinearity problems can be ruled out in our data. The results of the Ordinal Regression Model are shown in Table 4.

Table 4: Results of the Ordinal Regression Model

\begin{tabular}{lllll}
\hline Independent variables & Model 1 & \multicolumn{3}{c}{ Model 2 } \\
& B & SE & $\boldsymbol{\beta}$ & SE \\
\hline \hline Airports with connection (control) & $2.26^{* * *}$ & 0.40 & $2.36^{* * *}$ & 0.48 \\
Travel agencies (control) & $0.61^{* *}$ & 0.21 & 0.27 & 0.24 \\
Cultural distance (H1) & & & $0.48^{* *}$ & 0.23 \\
Heritage wealth (H2) & & & $2.43^{* * *}$ & 0.62 \\
Tourism infrastructures (H3) & & 0.03 & 0.26 \\
Security (H4) & & 0.06 & 0.39 \\
Chinese population (H5) & & $2.12^{* *}$ & 0.99 \\
\hline Chi-square & $54.68^{* * *}$ & & $83.76^{* * *}$ & \\
$\mathbf{N}$ & 47 & & 47 & \\
$* \mathrm{p}<0.05, * * \mathrm{p}<0.01, * * * \mathrm{p}<0.001$ & & & & \\
\hline \hline
\end{tabular}

Table 4 reports two models. Model 1 only contains control variables, and Model 2 incorporates independent variables. Model 1 is statistically significant (Chi-square $=54.68$, 
$\mathrm{p}<0.001$ ), which implies that control variables (flight connections with China and authorized travel agencies) help explain the dependent variable (number of Chinese tourists). Model 2 includes independent variables and is also significant (Chi-square $=83.76, p<0.001)$. Our results show that both greater cultural distance and greater heritage wealth are positively associated with the number of Chinese tourists who have decided to visit each country. Thus, hypotheses 1 and 2 are not rejected.

As pointed out by McKercher and du Cros (2003), people from countries which are very distant from a cultural point of view are the ones most strongly motivated to travel for cultural reasons and those who demand to live more intense experiences, as is the case with Chinese tourists. Li et al. (2011) suggest that Chinese tourists show great interest in the local culture and customs. They seek to take part in local events, festivals and shows, as Yang et al. (2011) report in their study about Chinese tourists during the Beer festival -Oktoberfest - in Munich (Germany). Moreover, our findings suggest that they travel with a motivation to enjoy landscapes, monuments, historic sites and traditions, recognized worldwide because they are World Heritage Sites.

Nevertheless, we must point out that a great majority of Chinese outbound tourists visit East or Southeast Asian countries yet. Thus, this result about culture distance should be delimited to the long haul European tourism context.

Furthermore, our results indicate that European countries with large communities of Chinese citizens are the ones most often visited by Chinese tourists. Thus, Hypothesis 5 is not rejected. This may be due either to the fact that cultural barriers are buffered by the presence of Chinese communities in the host country or to the fact that their motivation to travel stems from a desire to visit relatives or friends. In contrast, neither tourism infrastructure development level nor destination security level seem to be factors related to the number of Chinese tourists received. Thus, hypotheses 3 and 4 are rejected. This may be because 
Chinese tourists think that, on the whole, all Europe has a high development level in tourism and security matters, from which can be deduced that these two are not discriminating factors when it comes to make a decision about visiting one European country instead of another.

Nevertheless, the extent to which infrastructures are adapted to the needs of Chinese tourists might be more determining than the actual level of development in those infrastructures. For example, Spain is a country where tourism infrastructures have quite a high level. However, they are hardly adapted to the needs of Chinese tourists. Regarding the adaptation of European countries to Asian tourism, Arlt (2011b) points out that in most cases, European countries would find themselves at the end of the process, in the stability stage according to the acculturation curve described by Hofstede et al. (2010); but Spain would still be at the beginning of the process, in the phase of euphoria. Li et al. (2011) found that some of the most outstanding complaints of Chinese tourists traveling abroad are the lack of hot drinking water, Chinese tea, toiletries in hotels (amenities) or Chinese food, as well as language-related difficulties.

As for the lack of statistical significance for destination security, the measure used might have influenced our result too. Future research papers could try to develop other measures better suited to the Chinese tourist's perception of security at each destination (mugging or theft in general, violence, riots, security at hotel establishments, etc.).

In relation to control variables, our results suggest that the existence of airports with flight connections is positively related to the attraction of Chinese outbound tourism -this being an important piece of information to be considered by public administrations and tourism industry entrepreneurs if they want to increase the number of Chinese tourists. Finally, the number of authorized travel agencies does not seem to impact on the decision to travel to the different European countries. This information can equally be useful because, in that case, it would be more interesting for travel agencies to set up offices in China in order to be able to 
get hold of Chinese outbound tourism once the requirements to set up businesses in that country have been relaxed.

\section{CONCLUSIONS}

According to forecasts, Europe will remain as one of Chinese tourists' favorite destinations in the coming years (Zhang, 2011). Therefore, it becomes necessary for each country to know the factors that are likely to influence the destination choice of this promising market. With this aim in mind, tourism destinations need to make greater efforts to understand the essential foundations of Chinese outbound tourism (Tse \& Hobson, 2008).

Our paper has dealt with the main characteristics of the Chinese tourism that heads for Europe seeking to identify some of the factors that may influence destination choice. Our results indicate that cultural distance, heritage wealth, the existence of a large Chinese community or the availability of flight connections are variables related to the number of Chinese tourists who visit each European country. Therefore, Chinese tourists could travel motivated by a desire to gain first-hand experiences, to get involved in local customs or to visit the historic and natural heritage sites in each country, which only make possible with good flight connection.

Although it is true that Chinese tourists, who travel in package tours, usually land in one country and travel by coach visiting different countries, it is also true that this trend has started to change in recent years, as explained above. In fact, Li et al. (2011) found that Chinese tourists increasingly prefer to visit fewer countries and spend more time in each one of them with the aim of being able to know and enjoy their local culture. Europe undoubtedly boasts a vast cultural wealth that is very attractive for Chinese tourists.

Consequently, tourism promotion needs to place more emphasis on European culture, not only its heritage but also the traditions of each destination, its festivities, customs, 
gastronomy, etc. The way in which cultural differences are considered in the design of marketing strategies will determine their effectiveness and benefits (Crotts, 2004). It is equally necessary for public administrations to promote the establishment of new flight connections with China. Only in that way will each country avoid being left behind in the attempts to attract a part of this promising market. On the other hand, when competing to attract Chinese tourists, European countries must not act exclusively as direct competitors; instead, they should try to promote joint initiatives, joining efforts and reinforcing Europe's image.

Within this framework of cooperation between European countries, it would become essential to develop measures and actions meant to adapt to the characteristics of the Chinese market, for instance, in order to promote all services and information in Chinese language. As Arlt (2011a) points out, if the world's tourism industry wants to take advantage of this market, it has to become familiar with the cultural differences that have a direct impact on tourist behavior. The knowledge of both cultures and the desire to explore new paradigms become necessary in order to meet Chinese tourists' needs.

Ideological, psychological, social and cultural barriers still exist in the countries that receive Chinese tourists, which prevent these host countries from accepting and understanding these tourists $(\mathrm{Li}, 2007)$. Therefore, this lack of knowledge makes it necessary to implement an action agenda; tourism firms and administrations should start by asking themselves questions such as: who are those tourists?, why do they travel to certain countries?; and what are their preferences regarding products and services?

This paper has contributed to make some progress in answering the previous questions, although it is necessary to carry on studying and analyzing the characteristics and preferences of a market that will become the world's first tourism power in the next few years. The main limitation faced in our study lies in the use of secondary data and in the difficulty to obtain 
detailed information for each country about tourism coming from China. This situation is expected to change in the future with the growing number of Chinese tourists who cross the borders of the different European countries. In that case, more and better information will be available, thus allowing the use of measures other than those applied here.

Collecting primary data from Chinese outbound tourism themselves would serve better to understand the decision making by the target respondents. It would be interesting not only to know the image that the potential Chinese tourists have about each one of the different European countries but also to check what they know and what they really find attractive about each country. This would to analyze the extent to which the promotion policies for these countries within the Chinese market are being effective, thus making it possible to launch campaigns much more oriented to emphasize those aspects of each European country which can turn out to be more attractive for Chinese tourists.

\section{REFERENCES}

Andreu, R., Claver, E., \& Quer, D. (2010). Tourism in China: A review of research in leading journals. Journal of China Tourism Research, 6 (4), 343-357.

Antonioli Corigliano, M. (2011). The outbound Chinese tourism to Italy: The new graduates' generation. Journal of China Tourism Research, 7 (4), 396-410.

Arlt, W.G. (2011a). El auge del turismo emisor de China: ¿qué esperan y cómo se comportarán 100 millones de nuevos turistas?, in Anuario Asia-Pacífico 2010 (2011edition), Barcelona: CIDOB, 327-334.

Arlt, W.G. (2011b). Asian tourism: Future challenges in a post-western world, II International Congress on Asian Tourism, Barcelona, 7-8 February 2011. 
Basala, S., \& Klenosky, D. (2001). Travel style preferences for visiting a novel destination: A conjoint investigation across the novelty-familiarity continuum. Journal of Travel Research, 40 (2), 172-183.

Buckley, P. J., Clegg, L. J., Cross, A. R., Liu, X., Voss, H., \& Zheng, P. (2007). The determinants of Chinese foreign direct investment. Journal of International Business Studies, 38 (4), 499-518.

China Tourism Academy (CTA) (2011). Annual Report of China Outbound Tourism Development 2011. Beijing: Tourism Education Press.

Crotts, J.C. (2004). The effect of cultural distance on overseas travel behaviors. Journal of Travel Research, 43 (1), 83-88.

Du, J., \& Dai, B. (2008). Annual Report of China Outbound Tourism Development 2006. Beijing: China Tourism Education Press.

Erramilli, M.K. (1991). The experience factor in foreign market entry behavior of service firms. Journal of International Business Studies, 22 (3), 479-501.

European Travel Commission (2011). Market Insights: China. Retrieved May 15, 2012, from European Travel Commission Web site: http://www.etc-corporate.org/marketintelligence/market-insights.html.

Hair, J.F., Anderson, R.E., Tatham, R.L., \& Black, W.C. (2005). Multivariate data analysis (fifth edition). UpperSaddle River (NJ): Prentice Hall International.

Hofstede, G. (1980). Culture's Consequences. International Differences in Work-Related Values. Newbury Park, CA: Sage Publications.

Hofstede, G., Hofstede, G.J., \& Minkov, M. (2010). Cultures and Organizations. Software of the Mind. Intercultural Cooperation and its Importance for Survival (3rd edition). New York: McGraw-Hill. 
ITB (2011). ITB World Travel Trends Report 2010/2011. Retrieved May 15, 2012, from ITB Berlin Convention Web $\quad$ site: $\quad$ http://www.itbkongress.de/en/AboutITBBerlinConvention/ITBLibrary/.

Jackson, M. (2001). Cultural influences on tourist destination choices of 21 Pacific rim nations, CAUTHE National Research Conference, 166-176.

Kim, S.S., Guo, Y., \& Agrusa, J. (2005). Preference and positioning analyses of overseas destinations by Mainland Chinese outbound pleasure tourists. Journal of Travel Research, 44 (2), 212-220.

Kogut, B., \& Singh, H. 1988. The effect of national culture on the choice of entry mode. Journal of International Business Studies, 19 (3), 411-432.

Lepp, A., \& Gibson, H. (2003). Tourist roles, perceived risk and international tourism. Annals of Tourism Research, 30 (3), 606-624.

Li, M. (2007). Modeling the travel motivation of Mainland Chinese outbound tourists, Thesis for the degree of Doctor of Philosophy of Purdue University, Indiana.

Li, X., Harrill, R. Uysal, M., Burnett, T., \& Zhan, X. (2010). Estimating the size of Chinese outbound travel market: A demand-side approach. Tourism Management, 31 (2), 250259.

Li, X., Lai, C., Harrill, R., Kline, S., \& Wang, L. (2011). When east meets west: An exploratory study on Chinese outbound tourists' travel expectations. Tourism Management, 32 (4), 741-749.

Lui, V., Kuo, Y., Fung, J., Jap, W., \& Hsu, H. (2011). Tacking Off. Travel and Tourism in China and Beyond. Retrieved May 15, 2012, from The Boston Consulting Group Web site: http://www.bcg.com

Ma, X.L., Ryan, C., \& Bao, J.G. (2009). Chinese national parks: differences, resources use and tourism product portfolios. Tourism Management, 30 (1), 21-30. 
McKercher, B., \& du Cros, H. (2003). Testing cultural tourism typology. International Journal of Tourism Research, 5 (1), 45-58.

Neter, J., Wasserman, W., \& Kutner, M.H. (1996). Applied Linear Regression Models. $3^{\text {rd }}$ edition. Chicago: Irwin.

Ng, S.I., Lee, J.A., \& Soutar, G.N. (2007). Tourists' intention to visit a country: The impact of cultural distance. Tourism Management, 28 (6), 1497-1506.

Ohio University (2012). Distribution of the ethnic Chinese population around the world. Ohio University Library and the Shao Center. Retrieved May 15, 2012, from Center for International Collections Databank, Ohio University Library Web site: http://cicdatabank.library.ohiou.edu/opac/population.php

Pacific Asia Travel Association (PATA) (1995). Tracking Asian outbound travel trends, Travel Industry Monitor, 63, 4-6.

Plog, S.C. (2001). Why destination areas rise and fall in popularity? Cornell Hotel and Restaurant Administration Quarterly, 42 (3), 13-24.

Poolprasert, N. (2009). The impact of political instability, destination image and cultural distance on tourist's intention to revisit or recommend: An example of Bangkok. Taiwan: National Cheng Kung University (Institute of International Management).

Quer, D., Claver, E., \& Rienda, L. (2012). Political risk, cultural distance, and outward foreign direct investment: Empirical evidence from large Chinese firms. Asia Pacific Journal of Management, forthcoming.

Qun, D., \& Jie, D. (2001). A study of Mainland China outbound tourism markets. Tourism Review, $56(1-2), 44-47$.

Reisinger, Y., \& Crotts, J.C. (2010). Applying Hofstede's national culture measures in tourism research: Illuminating issues of divergence and convergence. Journal of Travel Research, 49 (2), 153-164. 
Sparks, B., \& Pan, G.W. (2009). Chinese outbound tourists: Understanding their attitudes, constraints and use of information sources. Tourism Management, 30 (4), 483-494.

Tomás, D. (2011). El turismo chino en España: la adaptación de destinos turísticos españoles al mercado turístico más grande del mundo. Retrieved May 15, 2012, from Fundación ICO Web site: http://www.fundacionico.es/index.php?id=355.

Tse, T.S.M., \& Hobson, J.S.P. (2008). The forces shaping China's outbound tourism. Journal of China Tourism Research, 4 (2), 136-155.

United Nations Educational Scientific and Cultural Organisation (UNESCO) (2012). World Heritage Centre. Retrieved May 15, 2012, from UNESCO Web site: http://whc.unesco.org/en/list

World Economic Forum (2011). Travel and Tourism Competitiveness Report 2011. Beyond the downturn. Retrieved May 15, 2012, from World Economic Forum Web site: www.weforum.org/ttcr

World Tourism Organisation (UNWTO) (2004). WTO in Asia and the Pacific. Retrieved May 15, 2012, from The World Tourism Organisation Web site: http://www.unwto.org/asia/news/en/pdf/wto_asia_pacific_2004.pdf

World Tourism Organisation (UNWTO) (2011). Tourism Highlights. 2011 Edition. Retrieved May 15, 2012, from The World Tourism Organisation Web site: http://mkt.unwto.org/en/content/tourism-highlights

Xiao, H. (2006). The discourse of power: Deng Xiaoping and tourism development in China. Tourism Management, 27(5), 803-814.

Xie, Y., \& Li, M. (2009). Development of China's outbound tourism and the characteristics of its tourist flow. Journal of China Tourism Research, 5(3), 226-242. 
Yang, X., Reeh, T., \& Kreisel, W. (2011). Cross-cultural perspectives on promoting festival tourism -An examination of motives and perceptions of Chinese tourists attending of Oktoberfest in Munich (Germany). Journal of China Tourism Research, 7(4), 377-295.

Yun, D., \& Joppe, M. (2011). Chinese perceptions of seven long-haul holiday destinations: Focusing on activities, knowledge, and interest. Journal of China Tourism Research, 7(4), 459-489.

Zhang, G. (2011). Analyses and forecasts on China's outbound tourism development 20102011, in Zhang, G., Song, R., \& Deqian, L. (eds.) (2011). Green Book of China's Tourism 2011. China's Tourism Development Analysis and Forecast (pp. 89-104). Beijing: SSAP and COTRI.

Zhang, G., Pine, R., \& Zhang, H.Q. (2000). China's international tourism development: present and future. International Journal of Contemporary Hospitality Management, 12(5), 282-290. 
APPENDIX 1

\begin{tabular}{|c|c|c|c|c|c|c|c|}
\hline $\begin{array}{l}\text { European } \\
\text { Country }\end{array}$ & $\begin{array}{c}\text { Number of } \\
\text { authorized } \\
\text { travel } \\
\text { agencies }\end{array}$ & $\begin{array}{l}\text { Airports with } \\
\text { flight } \\
\text { connections }\end{array}$ & $\begin{array}{c}\text { Number of } \\
\text { Chinese } \\
\text { inhabitants }\end{array}$ & $\begin{array}{c}\text { T\&T } \\
\text { regulatory } \\
\text { framework }\end{array}$ & $\begin{array}{l}\text { T\&T business } \\
\text { environment } \\
\text { and } \\
\text { infrastructure }\end{array}$ & $\begin{array}{l}\text { Number of } \\
\text { World } \\
\text { Heritage } \\
\text { Sites }\end{array}$ & $\begin{array}{l}\text { Kogut } \\
\text { \&Singh's } \\
\text { Index }\end{array}$ \\
\hline Russia & 283 & 3 & 680,000 & 4.5 & 4.1 & 26 & 2.08 \\
\hline France & 409 & 1 & 300,000 & 5.7 & 5.3 & 47 & 3.12 \\
\hline Germany & 815 & 3 & 111,000 & 5.7 & 5.6 & 36 & 2.11 \\
\hline Italy & 1051 & 2 & 188,352 & 5 & 4.8 & 50 & 2.81 \\
\hline Switzerland & $\ldots$ & 1 & 13,286 & 4.2 & 3.1 & 11 & 2.78 \\
\hline Austria & 90 & 1 & 40,000 & 5.9 & 5.2 & 9 & 3.61 \\
\hline Holland & 66 & 1 & 80,000 & 5.5 & 5.1 & 9 & 4.28 \\
\hline United Kingdom & 126 & 1 & 250,000 & 5.3 & 5.3 & 28 & 4.37 \\
\hline Spain & 91 & 1 & 166,223 & 5.3 & 5.3 & 55 & 3.00 \\
\hline Belgium & 148 & 1 & 30,000 & 5.5 & 4.7 & 19 & 3.45 \\
\hline Czech Republic & 112 & 0 & 5,173 & 5.3 & 4.6 & 16 & 1.71 \\
\hline Denmark & 25 & 1 & 10,368 & 5.5 & 5.1 & 4 & 5.77 \\
\hline Finland & 77 & 1 & 6,591 & 5.7 & 4.8 & 7 & 4.20 \\
\hline Greece & 1849 & 0 & 200 & 5.1 & 4.8 & 18 & 4.05 \\
\hline Sweden & 18 & 1 & 21,788 & 5.7 & 5.1 & 14 & 5.04 \\
\hline Turkey & 291 & 1 & 60,000 & 4.6 & 4 & 19 & 2.72 \\
\hline Hungary & 37 & 1 & 11,187 & 5.3 & 4.3 & 10 & 3.60 \\
\hline Portugal & 167 & 0 & 25.000 & 5.5 & 4.8 & 14 & 4.64 \\
\hline Poland & 91 & 0 & 499 & 4.9 & 3.8 & 13 & 3.66 \\
\hline Norway & 27 & 0 & 2,000 & 5.7 & 4.8 & 7 & 5.05 \\
\hline Romania & $\ldots$ & 0 & 1,898 & 4.9 & 3.8 & 9 & 2.32 \\
\hline Ukraine & $\ldots$ & 1 & $\ldots$ & 4.6 & 3.5 & 5 & 2.09 \\
\hline Croatia & 12 & 0 & $\ldots$ & 5 & 4.6 & 19 & 1.77 \\
\hline Slovakia & 40 & 0 & 1,718 & 5.1 & 4 & 8 & 1.49 \\
\hline Slovenia & 7 & 0 & 806 & 5.2 & 4.7 & 2 & 3.13 \\
\hline Bulgaria & 248 & 0 & 442 & 4.8 & 4.3 & 11 & 1.62 \\
\hline Iceland & 70 & 0 & 100 & 5.9 & 5.4 & 2 & 5.54 \\
\hline Ireland & $\ldots$ & 0 & 20,000 & 5.7 & 4.9 & 2 & 5.00 \\
\hline Latvia & 2 & 0 & 251 & 5.1 & 4.4 & 4 & 3.20 \\
\hline Luxembourg & 1 & 0 & 6,500 & 5.5 & 5.4 & 2 & 2.59 \\
\hline Lithuania & 47 & 0 & 396 & 5.1 & 4.2 & 7 & 2.34 \\
\hline Albania & $\ldots$ & 0 & $\ldots$ & 4.8 & 3.3 & 3 & 1.12 \\
\hline Armenia & $\ldots$ & 0 & $\ldots$ & 4.8 & 3.1 & 5 & 2.46 \\
\hline Azerbaijan & $\ldots$ & 0 & $\ldots$ & 4.7 & 3.3 & 2 & 2.46 \\
\hline Belarus & $\ldots$ & 0 & $\ldots$ & $\ldots$ & $\ldots$ & 4 & 2.11 \\
\hline $\begin{array}{l}\text { Bosnia and } \\
\text { Herzegovina }\end{array}$ & $\ldots$ & 0 & $\ldots$ & 4.2 & 3.1 & 2 & 1.95 \\
\hline Estonia & 20 & 0 & $\ldots$ & 5.5 & 5.1 & 2 & 1.96 \\
\hline Cyprus & 93 & 0 & 720 & 5.3 & 5.1 & 5 & 4.69 \\
\hline Georgia & $\ldots$ & 0 & $\ldots$ & 5.1 & 3.2 & 4 & 3.52 \\
\hline Liechtenstein & $\ldots$ & 0 & $\ldots$ & .. & & 0 & 2.11 \\
\hline Macedonia & $\ldots$ & 0 & $\ldots$ & 4.8 & 3.5 & 0 & 2.03 \\
\hline Malta & 121 & 0 & 725 & 5.7 & 4.9 & 3 & 4.29 \\
\hline Moldova & $\ldots$ & 0 & $\ldots$ & 4.2 & 2.8 & 1 & 1.74 \\
\hline Monaco & $\ldots$ & 0 & $\ldots$ & .. & $\ldots$ & 0 & 3.12 \\
\hline Montenegro & 6 & 0 & $\ldots$ & 5.1 & 4.2 & 2 & 1.69 \\
\hline San Marino & $\ldots$ & 0 & $\ldots$ & .. & $\ldots$ & 1 & 2.81 \\
\hline Serbia & 6 & 0 & $\ldots$ & 4.6 & 3.4 & 4 & 2.34 \\
\hline
\end{tabular}

